\title{
Experimental and Numerical Analyses of Single Pedestrian Walking on a Hollow Core Concrete Floor
}

\author{
Fangzhou Liu ${ }^{1} \cdot$ Jean-Marc Battini ${ }^{1} \cdot$ Costin Pacoste $^{1,2}$
}

Received: 14 February 2018 / Revised: 14 August 2018 / Accepted: 27 August 2018 / Published online: 4 September 2018

(c) The Author(s) 2018

\begin{abstract}
The purpose of this paper is to study experimentally and numerically the dynamic response of a hollow core concrete slab due to a single pedestrian. To achieve this aim, a test structure consisting of six hollow core concrete elements of dimension $10 \mathrm{~m} \times 1.2 \mathrm{~m}$ has been built. A finite element model of the structure based on orthotropic shell elements has been implemented. The accuracy of the finite element model has been assessed by reproducing numerically hammer-impact tests. For that, the experimental impact load has been imported to the finite element model. Very good agreements between experimental and numerical results have been obtained. Then, three different single pedestrian walking paths have been tested experimentally. Each of these paths has been reproduced numerically using four numerical load models taken from the literature. The results show that the four pedestrian loads give rather different numerical results regarding the amplitudes of the acceleration for each mode. In addition, a small change in the numerical parameters of the slab can give large differences in the numerical results. This shows that an accurate numerical modelling of a single pedestrian loading is not an easy task. The results show also that during transversal and diagonal walking paths, the vibrations due to the torsional mode of the slab can be higher than the ones due to the lowest bending mode.
\end{abstract}

Keywords Hollow core concrete slab $\cdot$ Experimental tests $\cdot$ Finite element model $\cdot$ Hammer-impact load $\cdot$ Single pedestrian walking

\section{Introduction}

Precast and prestressed hollow core slabs, see Fig. 1, are often used, particularly in Sweden, in the construction of floors for high-rise apartments, multi-story buildings, shopping malls, offices or parking garages. The main advantage of these slabs is that the combination of low self-weight

Jean-Marc Battini

jean-marc.battini@byv.kth.se

http://www.kth.se

Fangzhou Liu

fangzhou@kth.se

http://www.kth.se

Costin Pacoste

costin.pacoste@elu.se

http://www.kth.se

1 Division of Structural Engineering and Bridges, Royal Institute of Technology (KTH), Brinellvägen 23,

11428 Stockholm, Sweden

2 ELU Konsult, Valhallavägen 117, 11531 Stockholm, Sweden and high strength makes it possible to design floors with long spans. Therefore, this implies that the slabs are also confronted with the issue of floor vibration serviceability, particularly the vibration from human activity. In fact, many practical cases in Sweden have shown that the length of the span is often limited by dynamic consideration and not by static criteria.

In the past years, some research concerning shear behaviour, structural behaviour, thermal performance and fire performance of hollow core concrete slabs has been addressed [1-7]. However, to the authors' knowledge, there are only a few research works in the literature concerning the dynamic response of hollow core floors. Natural frequencies of a solid slab and a hollow core slab have been compared by Jendzelovsky and Vrablova [8]. Marcos et al. [9] presented a parametric study on the vibration sensitivity of hollow core slabs. They found that the most important parameter for the first natural frequency is the span. However, these two studies were only numerical and the results were not confirmed by experimental investigations. Laboratory tests with three simply supported elements were conducted by Lund 


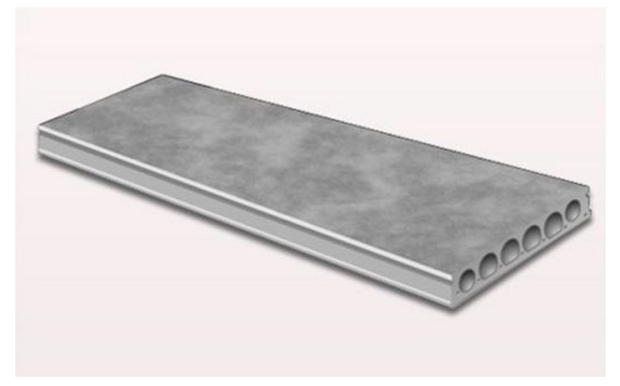

Fig. 1 Hollow core concrete slab

Technical University in Sweden and were presented in the Master thesis of Johansson [10]. However, the mode shapes associated to the natural frequencies were not determined from the measured data, and consequently, the dynamic behaviour of the slab cannot be really understood.

The main purpose of the present work is to study experimentally and numerically the dynamic response of a built hollow core concrete slab due to a single pedestrian. Three different walking paths and four numerical models taken from the literature for the single pedestrian load are considered. The numerical results are filtered at 1/3 octave band and then processed using a running RMS method. A complete description of the experimental tests and results can be found in [11]. The finite element shell model of the concrete slab has been developed and calibrated in a previous work which has been published by Magazine of Concrete Research [12].

\section{Experimental Tests}

\subsection{Hollow Core Concrete Slab}

The experimental structure was built at the production plant of the company Contiga, a leading supplier of precast concrete structures in Sweden. The slab consisted of six hollow core elements of dimension $10 \mathrm{~m} \times 1.2 \mathrm{~m} \times 0.27 \mathrm{~m}$ each, supported by horizontal and vertical steel beams, see Figs. 2 and

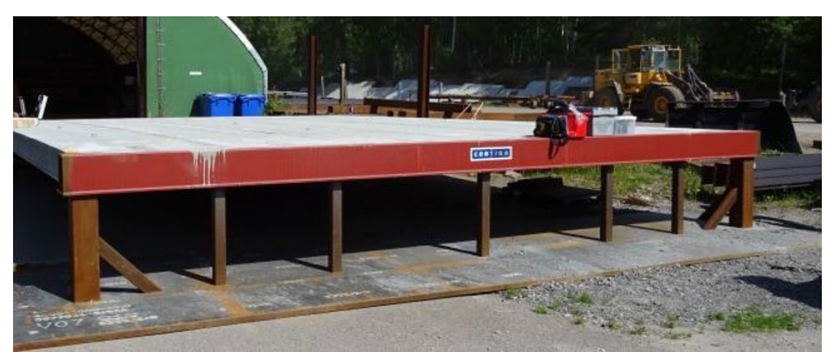

Fig. 2 Experimental structure
3. The connections (joints) between the slabs were poured with grouted concrete. The connection between the concrete floor and the horizontal steel beams was performed through steel connectors welded to the horizontal steel beam and anchors steel bars casted on the concrete floors, see Fig. 4. A 50-mm height concrete topping was added on the slab 30 days after the casting of the joints. The strength class of the concrete was $\mathrm{C} 45 / 55$ for the hollow core elements and the joints and C30/37 for the topping. Additional information about the test structure can be found in [11].

Ten accelerometers, see Fig. 3, were used to record acceleration data. As shown in Fig. 3, accelerometers A1 to A9 were installed at the typical points of $1 / 4$ span, $1 / 2$ span and $3 / 4$ span of the slab to measure the vertical accelerations. Accelerometer A10 was installed on the side of one steel beam and registered the horizontal accelerations. Additional information regarding the accelerometers can be found in [11]. The sampling frequency was chosen at 2048 points per second.

The experimental tests were divided in three phases: in Phase1, the joints were casted but not the topping; in Phase2, the concrete topping was in place; in Phase 3, all the intermediate steel columns were removed and the horizontal steel beams were then only supported at their ends.

\subsection{Harmonic Vibration Test}

A sinusoidal force with a peak amplitude of $25 \mathrm{~N}$ and a frequency range from 4 to $35 \mathrm{~Hz}$ has been applied to the structure. This test, which is described in [11], was then used to calibrate the finite element model of the slab. The updating procedure and the calibration are presented in $[11,12]$.

\subsection{Hammer-Impact Test}

The slab was subjected to an impact force applied using a heavy-duty impact hammer (see Fig. 5) of Type 8208. The impact loading was applied at position H1, see Fig. 3.

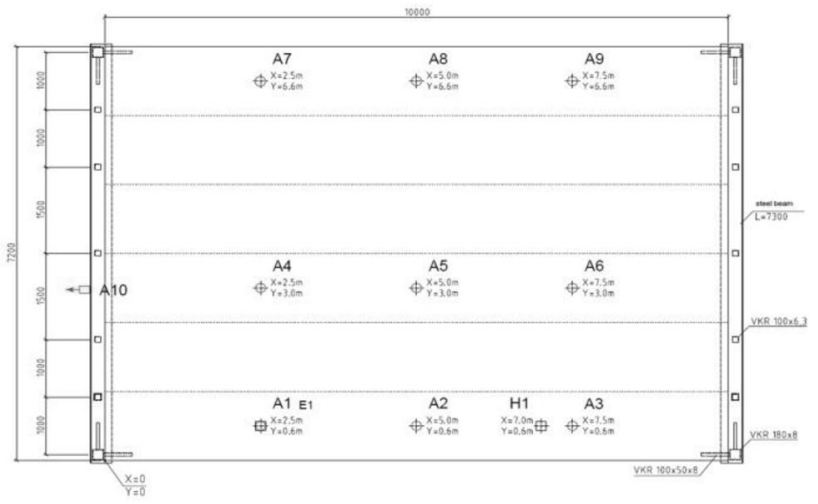

Fig. 3 Location of the accelerometers A1 to A10 and the exciting loads 
Fig. 4 Cross-section of the horizontal steel beams and steel connectors (a) and Grout concrete, steel connectors and steel bars (b)

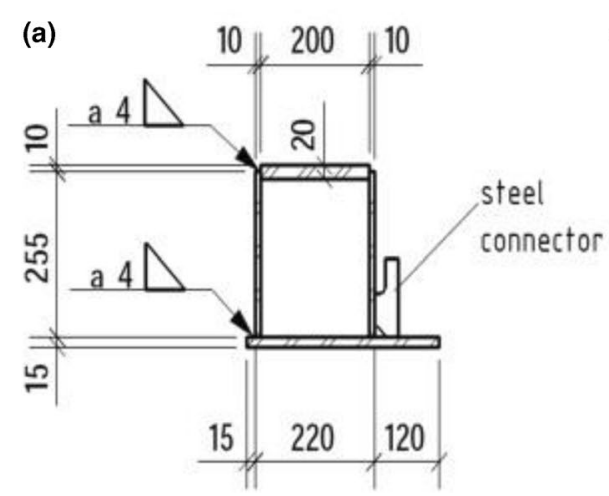

(b)

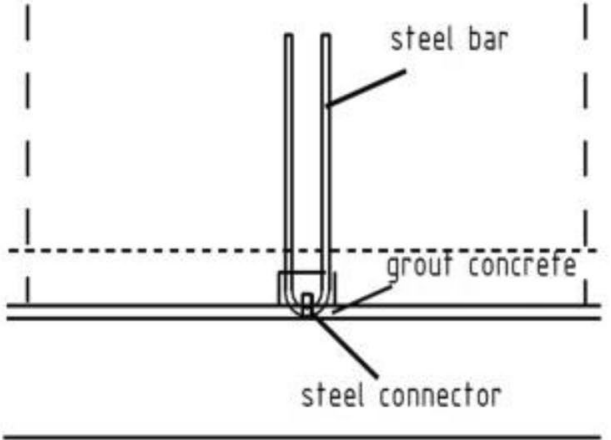

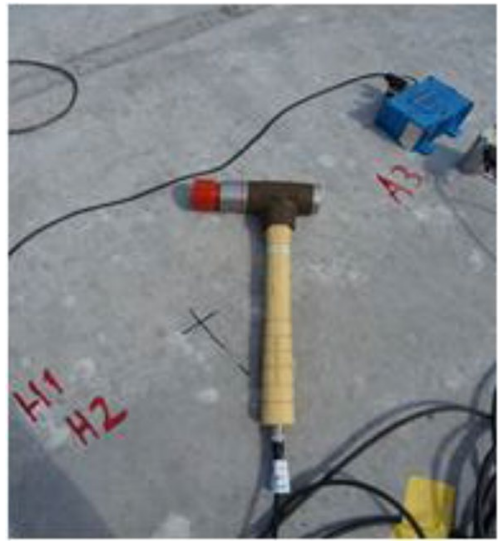

Fig. 5 Heavy-duty impact hammer (Type8208)
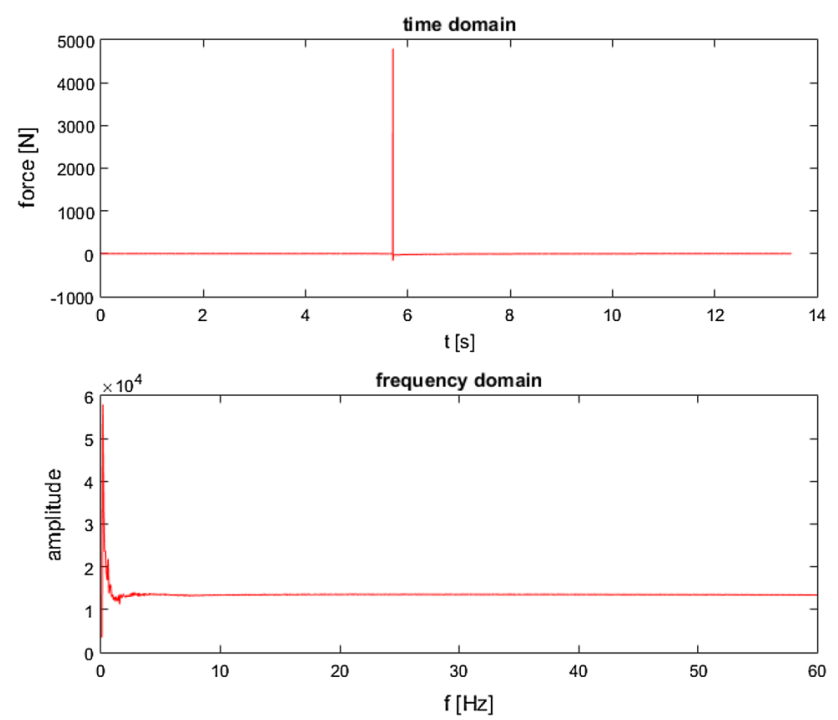

Fig. 6 The imposed signal of the impact force hammer

The hammer has built-in electronics and is designed to excite and measure impact forces on medium to very large structures. It gives an impulse load of very short duration,

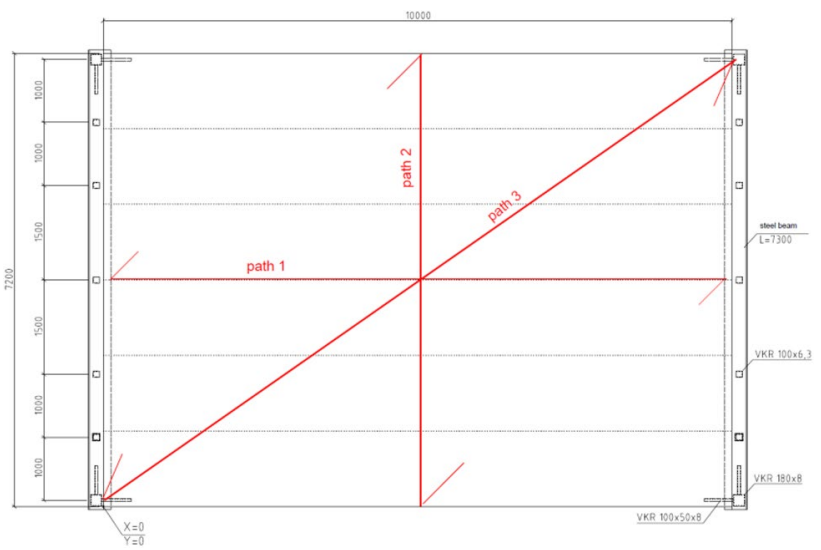

Fig. 7 Single pedestrian walking paths

and consequently, frequencies up to $50 \mathrm{~Hz}$ can be excited. The imposed signals both in time domain and frequency domain are shown in Fig. 6.

\subsection{Single Pedestrian Walking}

The tests of a single pedestrian $(85 \mathrm{~kg})$ walking on the slab were conducted for phases 2 and 3, i.e. after the casting of the topping. Three different paths were considered, see Fig. 7. The walking frequency was $2.2 \mathrm{~Hz}$ in Phase 2 and $2 \mathrm{~Hz}$ in Phase3, to excite high level of vibration at the lowest natural frequency of the slab.

\section{Finite Element Modelling}

\subsection{Structure}

A FE model of the structure was developed using the finite element programme ABAQUS, see Fig. 8. The concrete part was modelled as one homogeneous plane using orthotropic shell elements, whereas the steel parts were modelled using isotropic shell elements. Four-node doubly curved shell elements S4 were used. A convergence study was carried out 


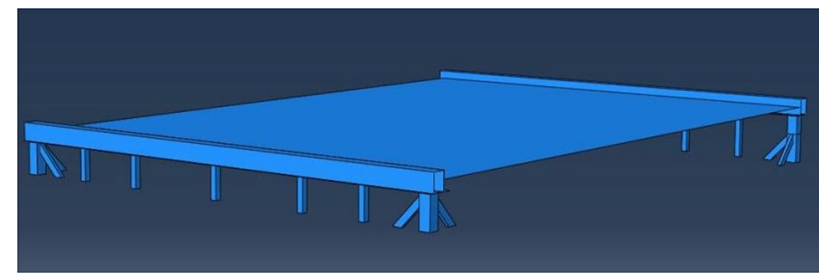

Fig. 8 3D finite element model

and an optimised element size of $0.05 \mathrm{~m}$ was chosen for both of concrete and steel parts. Tie constraints were used to connect the steel columns to the horizontal steel beams and the steel columns to the diagonal steel bars. The concrete part was directly tied on the vertical surface of the two horizontal steel beams. The reinforcement and the prestressing were not considered since they do not have a significant influence on the dynamic response of the slab.

The thickness and density of the shell elements $(0.300 \mathrm{~m}$ and $1603.6 \mathrm{~kg} / \mathrm{m}^{3}$ ) have been determined by considering the moment of inertia of the cross-section of the concrete slab in the voids direction and by performing a numerical analysis of this cross-section using four-node bilinear twodimensional warping elements WARP2D4. This procedure is described in [12].

The material properties of the steel were taken as: $E=210$ $\mathrm{GPa}, \nu=0.3, \rho=7850 \mathrm{~kg} / \mathrm{m}^{3}$. For the concrete slab, orthotropic shell elements with a lamina material have been used. The following parameters have been taken: $E_{1}=36$ $\mathrm{GPa}, E_{2}=16.2 \mathrm{GPa}, v_{12}=0.2, G_{12}=12.1 \mathrm{GPa}, G_{13}=18 \mathrm{GPa}$, $G_{23}=8.1 \mathrm{GPa}$. Direction 1 is along the voids and direction 2 is perpendicular to direction 1 . The values of these parameters have been determined in [12] by calibrating the finite element model against the experimental results obtained with the harmonic excitation.

\subsection{Single Pedestrian Walking Loads}

Four types of single pedestrian walking loads (see Fig. 9b) of pace frequency $2 \mathrm{~Hz}$ were taken from the literature (EU project [13], Setra [14], Chen [15] and Pan [16]) and applied in Phase 3. To fit the pace frequency of $2.2 \mathrm{~Hz}$ used in Phase2, the walking load time history of the second step (right foot) was moved forward $0.05 \mathrm{~s}$, see Fig. 9a. These frequencies were calculated so that they correspond to $1 / 3$ of the lowest measured natural frequencies.

Single footfall forces (walking load time histories of right or left foot) were applied at the nodal points of the FE mode as proposed in Pan [16]. The distance between adjacent nodal points was taken as the average stride length of each walking test.
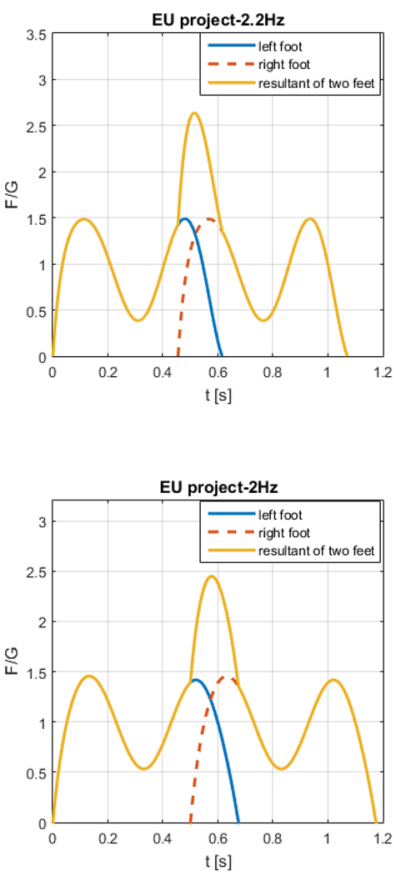
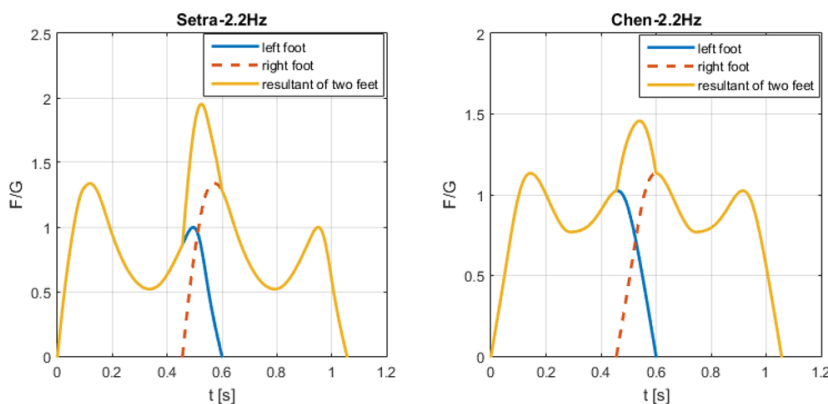

(a) phase2: walking pace frequency $2.2 \mathrm{~Hz}$
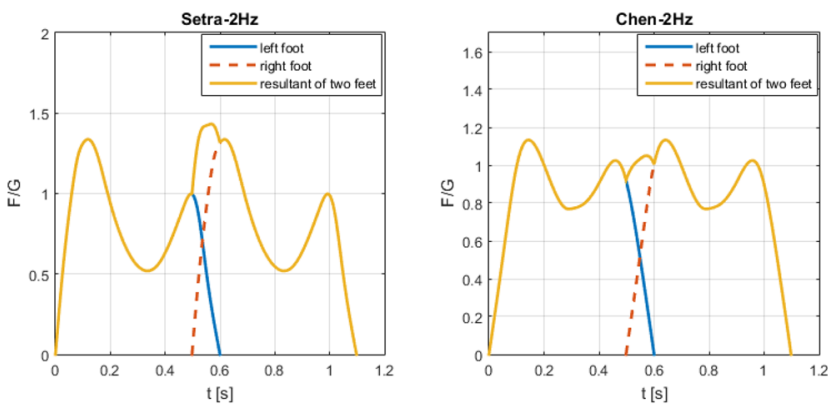

(b) phase3: walking pace frequency $2 \mathrm{~Hz}$
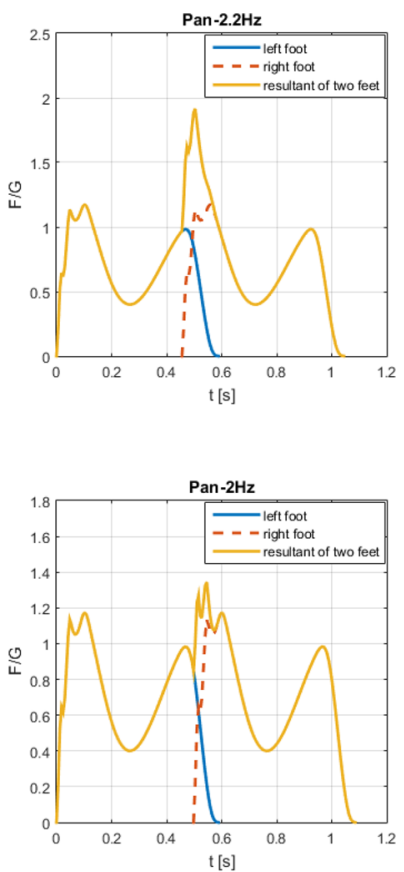

$\mathrm{t}[\mathrm{s}]$

Fig. 9 Four types of single pedestrian walking load time histories 


\section{Comparison Between Experimental And Numerical Results}

The obtained experimental natural frequencies and associated damping and mode shapes can be found in [11].

The experimental tests were analysed numerically using a modal superposition procedure including the ten lowest modes. Both the experimental results and numerical results were processed using Fast Fourier Transforms. An alternative processing method that filtering the signals in 1/3 octave band was also used. Moreover, the filtered signals were processed again using a running r.m.s. method [17]. The running r.m.s. method takes into account occasional shocks and transient vibration using a short integration time constant,

$a_{\mathrm{w}}\left(t_{0}\right)=\sqrt{\frac{1}{\tau} \int_{t_{0}-\tau}^{t_{0}}\left[a_{\mathrm{w}}(t)\right]^{2} \mathrm{~d} t .}$

As recommended in ISO 2631-1 [17] and ISO 10137 [18], the value $=1 \mathrm{~s}$ was taken.

The vibration magnitude is determined as a maximum transient vibration value (MTVV) which is defined by:

$\operatorname{MTVV}=\max \left[a_{\mathrm{w}}\left(t_{0}\right)\right]$.
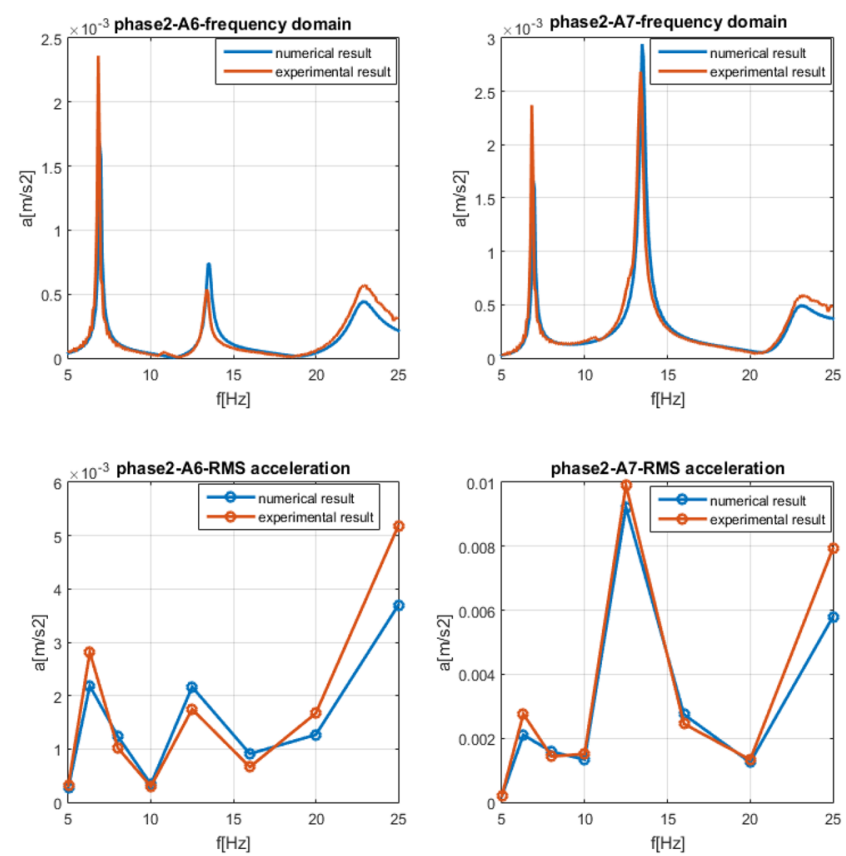
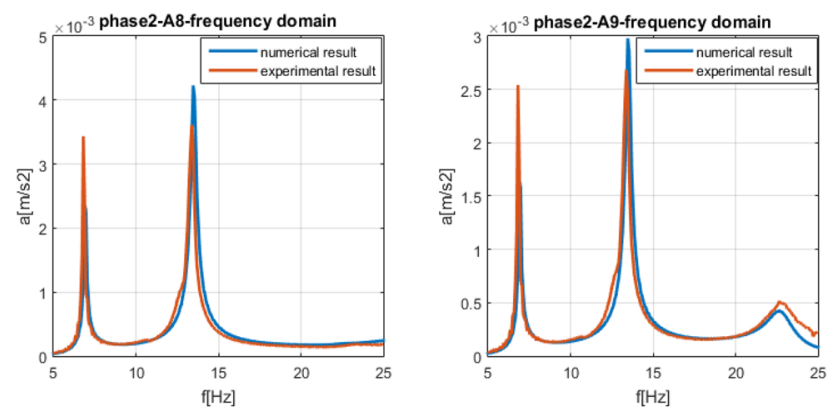

\subsection{Hammer-Impact Test}

The numerical analysis was performed by importing the registered experimental impact load time history in the FE model. The results are presented in Fig. 10 for Phase 2 and Fig. 11 for Phase 3. A very good agreement between numerical and experimental results is obtained. This shows that the numerical model of the slab is accurate.

\subsection{Single Pedestrian Walking Tests}

Experimental and numerical results for single pedestrian walking tests are presented in Fig. 12 for Phase 2 and Fig. 13 for Phase 3. The experimental results (green lines) show, as expected, that the first mode (bending) is excited for each walking path. They show also that the second mode (torsion) is excited for walking paths 2 and 3. Moreover, in Phase2, the amplitudes of the acceleration are higher for the torsional mode than for the bending mode.

The numerical results show that the four single pedestrian walking load models excite the first two modes. However, a large difference between the four models regarding the amplitude of the accelerations can be observed. In particular, the load model EU project [13] overestimates the amplitudes of the first bending mode in all the analyses. In Phase 2, the results obtained with the load models, Setra [14] and Pan [16], are also very high compared to the experimental results for mode 1. In Phase 3, the three load models, Pan [16], Chen [15] and Setra [14], give lower results compared to experiments for the first mode. None of the load model
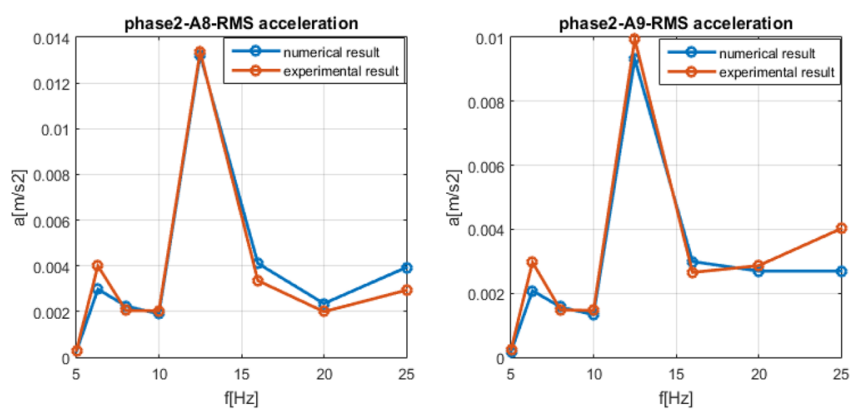

Fig. 10 Phase 2: FFT accelerations and RMS accelerations at centre frequencies of 1/3 octave bands 

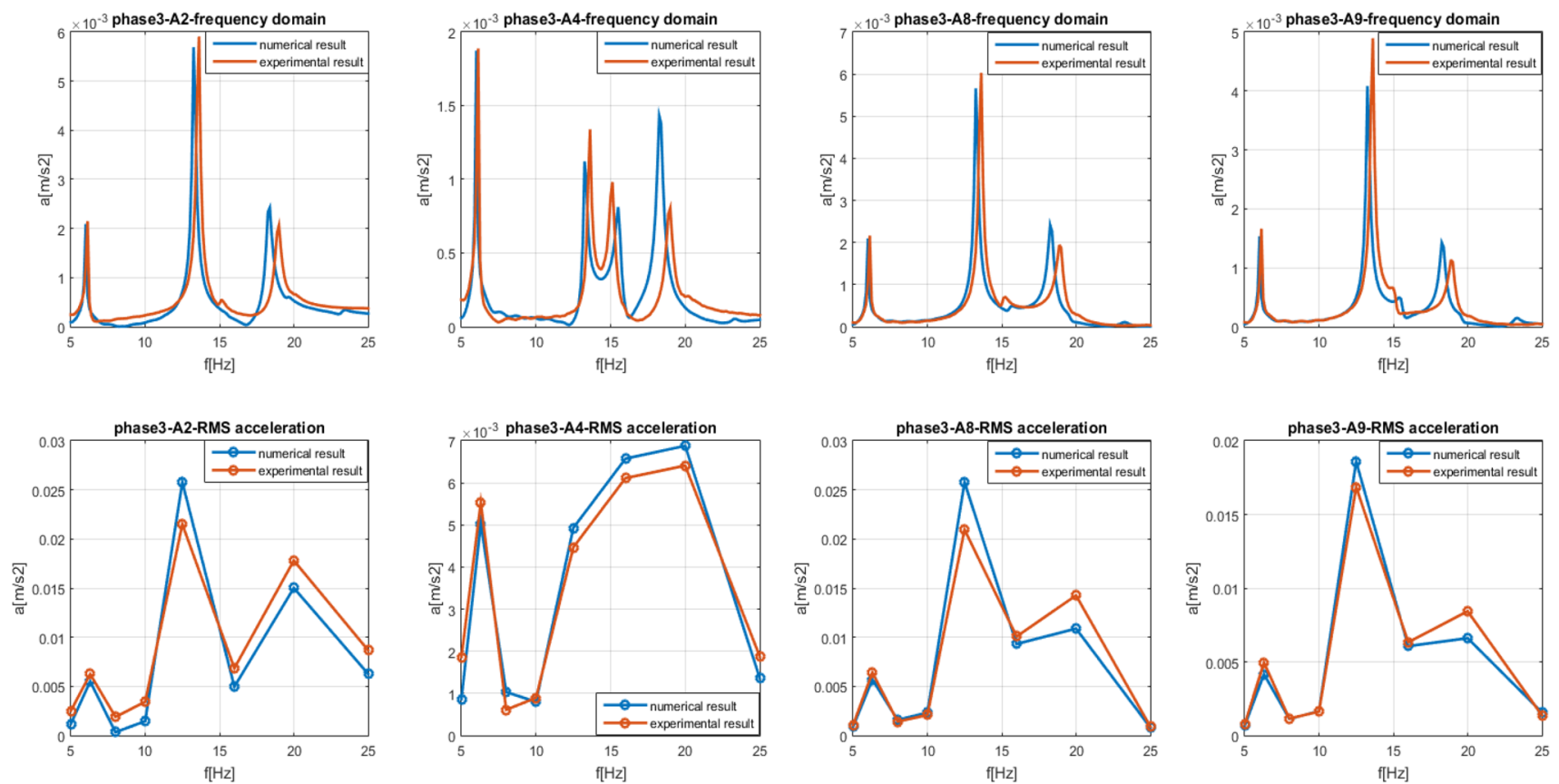

Fig. 11 Phase 3: FFT accelerations and RMS accelerations at centre frequencies of 1/3 octave bands
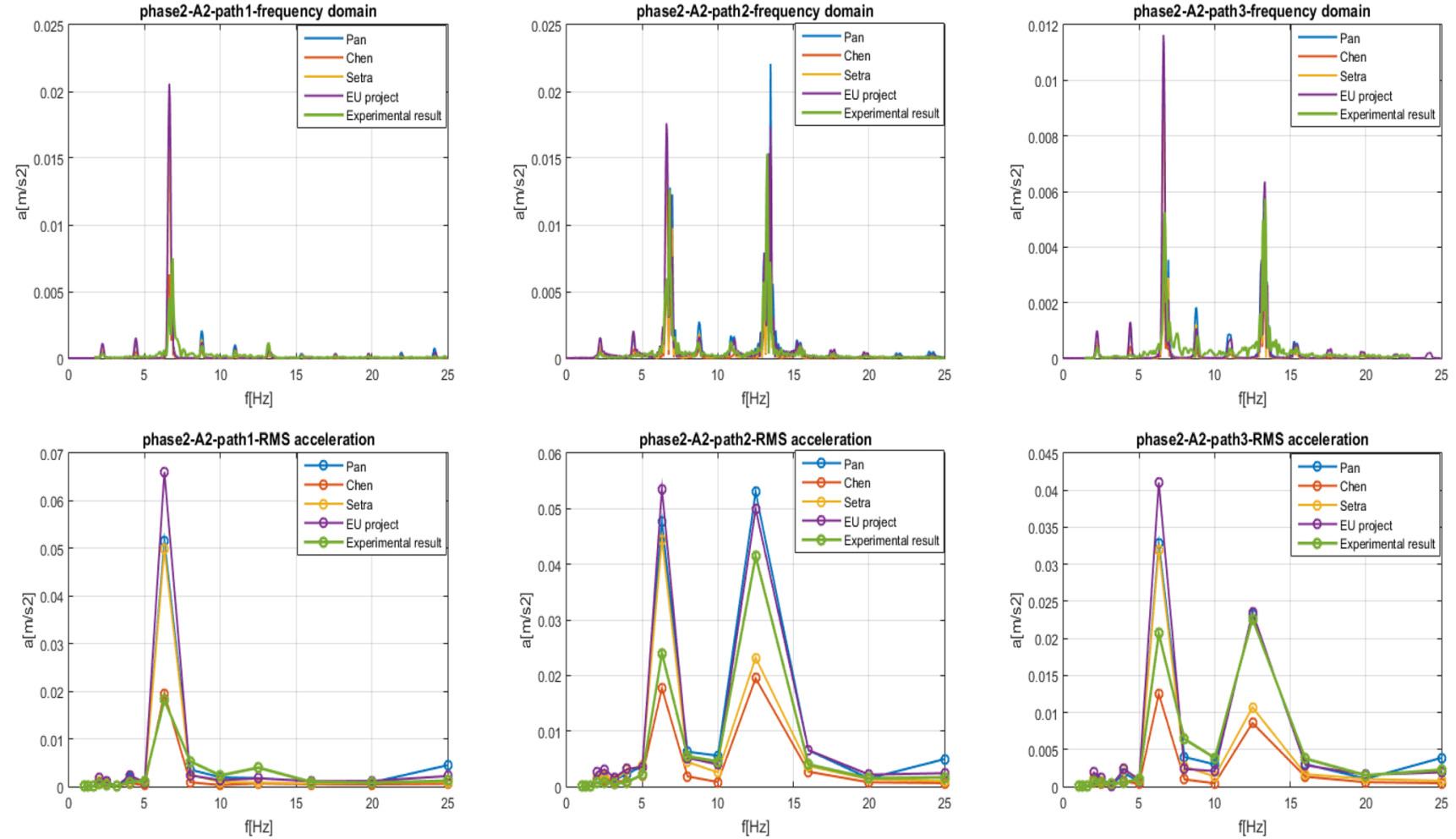

Fig. 12 Phase 2: FFT accelerations and RMS accelerations of single pedestrian walking at each path 

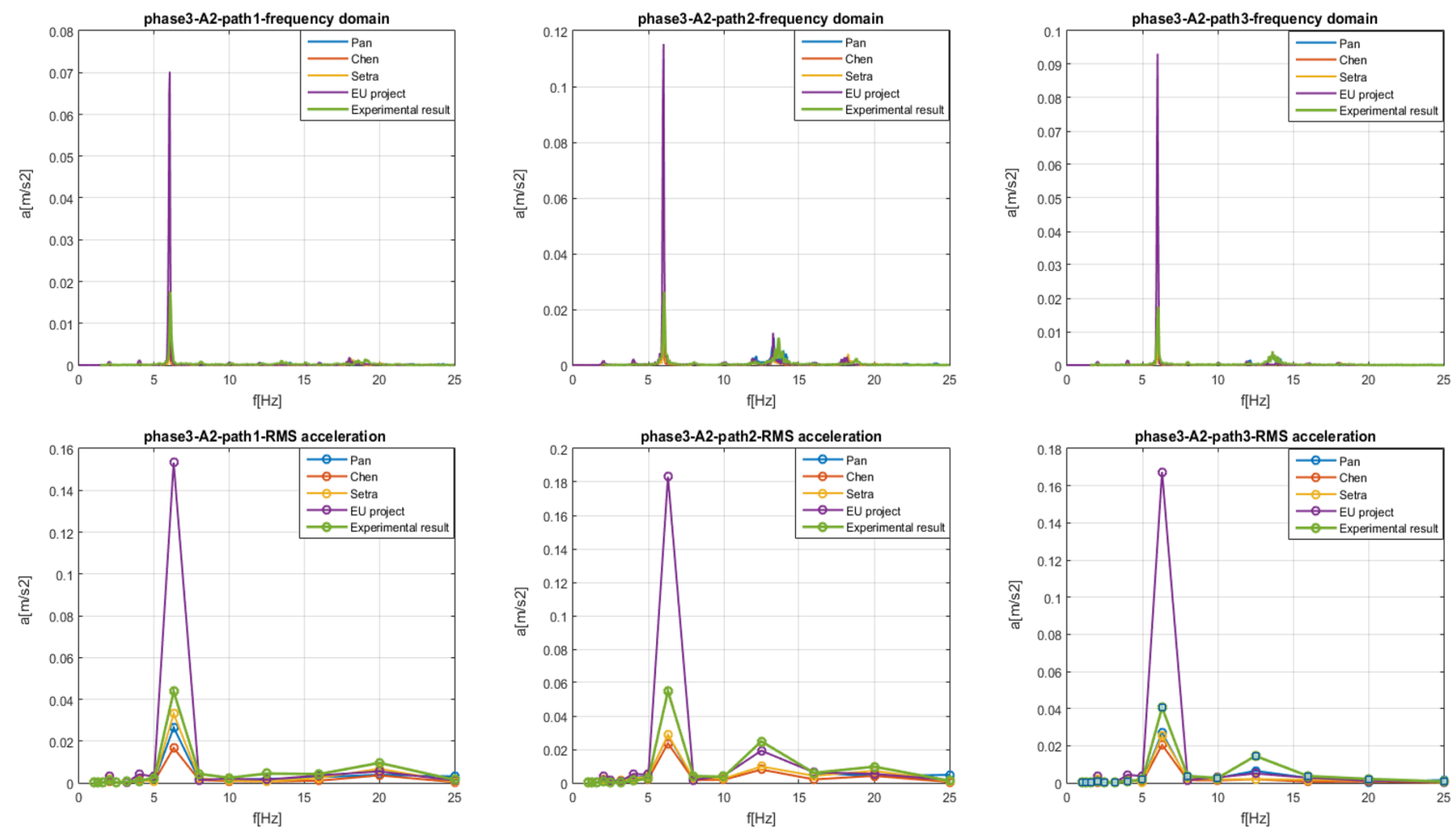

Fig. 13 Phase 3: FFT accelerations and RMS accelerations of single pedestrian walking at each path

gives good results in both Phases 2 and 3. However acceptable results were obtained using the load model Chen [15] in Phase 2 and the load model Pan [16] in Phase 3.

In the authors' opinion, the high acceleration level for the torsional mode in Phase 2 is due to the fact that the sixth order harmonic of the footstep $(2.2 \mathrm{~Hz})$ coincides

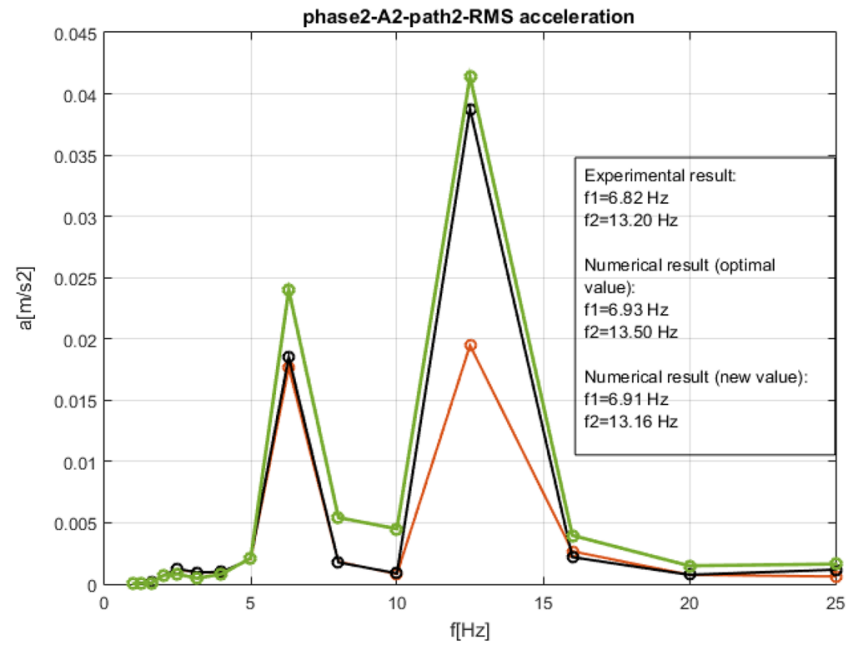

-C Chen-optimal value: $E 1=36 \mathrm{Gpa}, \mathrm{E} 2=16.2 \mathrm{Gpa}, \mathrm{G} 12=12.1 \mathrm{Gpa}$
- Chen-new value: $\mathrm{E} 1=36 \mathrm{Gpa}, \mathrm{E2}=10.8 \mathrm{Gpa}, \mathrm{G} 12=11.8 \mathrm{Gpa}$ - Cxen-new value: $:$ El with the experimental natural frequency in torsion $(13.2 \mathrm{~Hz})$. To valid this hypothesis, the parameters $E_{2}$ and $G_{12}$ of the concrete slab have been changed so that the numerical frequency for the torsional mode in Phase 2 matches exactly the experimental one. As a matter of fact, the optimal material parameters given in Sect. 4.1

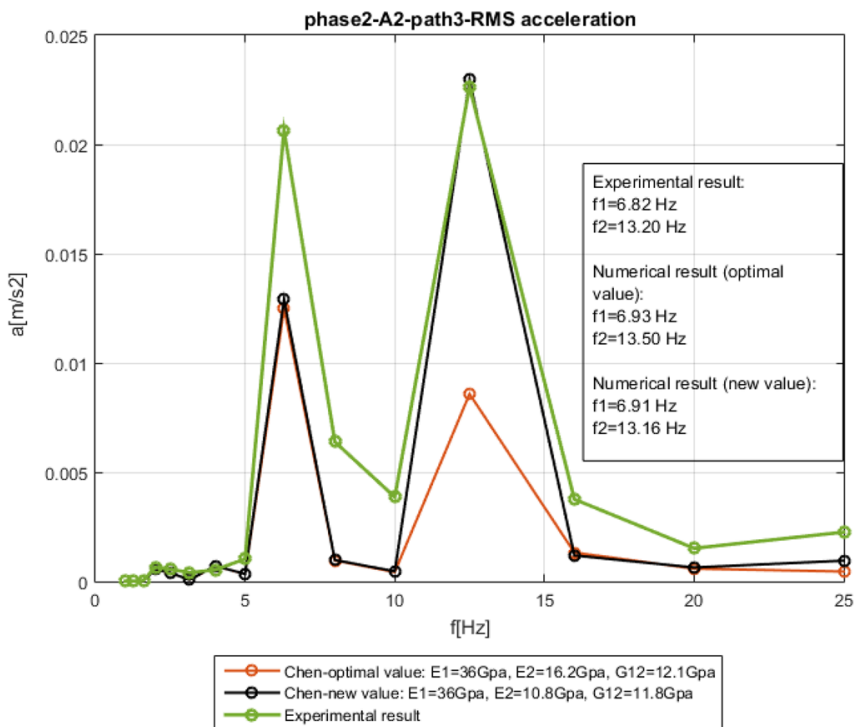

Fig. 14 Comparison of vibration magnitudes 
were obtained by considering both Phases 2 and 3 and also higher modes. One of the results is shown in Fig. 14 for the load model Chen [15]. With the new values for the material parameters, the amplitude of acceleration increases significantly for the second mode (torsion). With this load model, very good agreements between experimental and numerical results are obtained for the torsional mode.

\section{Conclusion}

In this paper, experimental and numerical results of a concrete slab consisting of six hollow core elements and excited by hammer-impact and single pedestrian walking loads have been presented.

The purpose of the hammer-impact tests was to verify the finite element model of concrete floor. Very good agreement between experimental and numerical results is obtained, both regarding the natural frequencies and the amplitudes of vibrations.

For the single pedestrian walking tests, three different walking paths have been considered. As expected, the first bending mode is excited in each path. However, and more surprising, the experimental results show that in Phase 2 and for walking paths 2 and 3 the amplitudes of acceleration are higher for the second mode (torsion) than for the first mode (bending). Additional numerical analyses have shown that this is probably due to the fact that the sixth order harmonic of the footstep $(2.2 \mathrm{~Hz})$ coincides with the natural frequency in torsion $(13.2 \mathrm{~Hz})$. This indicates that the dynamic analysis cannot be limited to the study of the lowest natural frequency of the floor.

Four single pedestrian walking load models taken from the literature have been implemented. All the four models excite the two lowest modes but large differences regarding the amplitude of the accelerations can be observed. In fact, although acceptable results compared to experiments are obtained with the load model Chen [15] in Phase 2 and the load model Pan [16] in Phase 3, none of the load model gives accurate results in both Phases 2 and 3. Besides, it has been observed that the amplitudes of vibrations are sensitive to the material properties of the concrete floor models: a small change a in the natural frequency can give large differences in the amplitudes of vibrations for the second mode.

Finally, the results obtained in this paper show that an accurate numerical modelling of a single pedestrian loading is not an easy task and that additional works are required to obtain simple but accurate pedestrian loads that can be used to study the dynamic response of hollow core concrete floors.

Acknowledgements The authors would like to thank the staff of company Contiga for giving us the possibility to perform the experimental tests at their production plant and also for the help during the tests. Many thanks also to Isabelle and Amanda Liljeström who planed and performed the experimental tests as part of their Master degree project, and to Kent Lindgren and the Company ACAD that were responsible for the data recording during the tests. Finally, the authors would like to thank the Ellen, Walter \& Lennart Hesselman Foundation for their financial support.

Funding Ellen, Walter \& Lennart Hesselman Foundation.

Open Access This article is distributed under the terms of the Creative Commons Attribution 4.0 International License (http://creativeco mmons.org/licenses/by/4.0/), which permits unrestricted use, distribution, and reproduction in any medium, provided you give appropriate credit to the original author(s) and the source, provide a link to the Creative Commons license, and indicate if changes were made.

\section{References}

1. Hegger J, Roggendorf T, Kerkeni N (2009) Shear capacity of prestressed hollow core slabs in slim floor constructions. Eng Struct 31:551-559

2. Girhammar UA, Pajari M (2008) Tests and analysis on shear strength of composite slabs of hollow core units and concrete topping. Constr Build Mater 22:1708-1722

3. Lam D, Elliott KS, Nethercot DA (2000) Parametric study on composite steel beams with precast concrete hollow core floor slabs. J Constr Steel Res 54:283-304

4. Faheem A, Ranzi G, Fiorito F (2016) A numerical study on the thermal performance of night ventilated hollow core slabs cast with micro-encapsulated PCM concrete. Energy Build 127:892-906

5. Aguado JV, Albero V, Espinos A (2016) A 3D finite element model for predicting the fire behavior of hollow-core slabs. Eng Struct 108:12-27

6. Venanzi I, Breccolotti M, D’Alessandro A, Materazzi AL (2014) Fire performance assessment of HPLWC hollow core slabs through full-scale furnace testing. Fire Saf J 69:12-22

7. Kakogiannis D, Pascualena F, Reymen B (2013) Blast performance of reinforced concrete hollow core slabs in combination with fire: Numerical and experimental assessment. Fire Saf J 57:69-82

8. Jendzelovsky N, Vrablova K (2015) Comparison of natural frequencies of hollow core slabs. Appl Mech Mater 769:225-228

9. Marcos LK, Carrazedo R (2014) Parametric study on the vibration sensitivity of hollow-core slabs floors. Proceedings of the 9th International Conference on Structural Dynamics, EURODYN

10. Johansson P (2009) Vibration of hollow core concrete elements induced by walking. Master thesis, Lunds Tekniska Högskola, Lunds Universitet

11. Liu F, Battini J, Pacoste C, Granberg A (2017) Experimental and numerical dynamic analyses of hollow core concrete floors. Structures 12:286-297

12. Liu F, Battini J, Pacoste C (2018) Finite shell element models for the dynamic analysis of hollow core concrete floor. Mag Concr Res

13. Sedlacek G, Heinemeyer C, Butz C, Völling B (2006) Generalisation of criteria for floor vibrations for industrial, office, residential and public building and gymnastic halls. European Communities, Luxembourg

14. Setra (2006) Footbridges-Assessment of vibrational behavior of footbridges under pedestrian loading. http://www.setra.equip ement.gouv.fr. Accessed 2006 
15. Chen J, Xu R, Zhang M (2014) Acceleration response spectrum for predicting floor vibration due to occupant walking. J Sound Vib 333:3564-3579

16. Pan T, ASCE M, You X, Lim CL (2008) Evaluation of floor vibration in a biotechnology laboratory caused by human walking. ASCE J Perform Constr Facil. https://doi.org/10.1061/ (ASCE)0887-3828(2008)22:3(122)

17. ISO 2631-1, Mechanical vibration and shock-Evaluation of human exposure to whole-body vibration-Part 1: General requirements
(1997), International Organization for Standardization, https:// www.iso.org/standard/7612.html. Accessed 1997

18. ISO 10137, Bases for design of structures-Serviceability of buildings and walkways against vibrations (2007), International Organization for Standardization, https://www.iso.org/standard/37070 .html. Accessed 2007 